\title{
Practice of contraception in this modern world: still a myth?
}

\author{
Reeta Bansiwal ${ }^{1}$, Pushpa Singh ${ }^{2}$, Shruti Bajpai
}

\author{
${ }^{1}$ Department of Obstetrics \& Gynaecology, VMMC \& Safdarjung Hospital, New Delhi-110029, India \\ ${ }^{2}$ Department of Obstetrics \& Gynaecology, Dr. RML Hospital and PGIMER, New Delhi-110001, India
}

Received: 14 March 2015

Accepted: 11 April 2015

\author{
*Correspondence: \\ Dr. Reeta Bansiwal, \\ E-mail: drreetabansiwal@gmail.com
}

Copyright: ( $)$ the author(s), publisher and licensee Medip Academy. This is an open-access article distributed under the terms of the Creative Commons Attribution Non-Commercial License, which permits unrestricted non-commercial use, distribution, and reproduction in any medium, provided the original work is properly cited.

\begin{abstract}
Background: Objective: To assess the attitude, knowledge and practice of contraception among MTP seekers women attending Family Planning OPD.

Methods: 150 women attending family planning clinic and requesting for Medical Termination of Pregnancy (MTP), were interrogated on a pre- structured questionnaire and their knowledge, attitude and practice about contraception were assessed.

Results: Of the women $80 \%$ women had some or the other knowledge of contraception but still $92(61.3 \%)$ were not using any contraception $92(61.3 \%), 54(36 \%)$ were using barrier method and only $4(2.6 \%)$ were used OCP's. The request for MTP was mainly on grounds of unplanned pregnancy and completed family in $57.3 \%$ cases followed by previous child small $42(28 \%)$. Of the women, only $38(25.3 \%)$ had heard about emergency contraceptives and only few had used them off and on. The various methods of contraception accepted by the women post abortion were IUDs by $91(61.3 \%)$ and female sterilization by 55 (36.6\%). Statistical analysis was done using SPSS software 15.

Conclusions: Practice of contraception is still a myth. There is a great need to strengthen the awareness among people by various programmes and the target group should be both males and females.
\end{abstract}

Keywords: Contraception, Medical abortion, Emergency contraception, Medical termination of pregnancy (MTP), Intrauterine devices (IDUs), Oral contraceptive pills (OCPs), Sterilization

\section{INTRODUCTION}

In this $21^{\text {st }}$ century where females have stepped on moon and even reached mars, there are still majority of females who are fighting for their right of reproduction and contraception. Knowledge of contraception is present among women but due to the interference of husband and family members they can't avail their right of reproduction. Contraception chosen is mostly husband dependent and ultimately the brunt of abortion comes to female. Induced abortions have always been of a great concern to medical practitioners worldwide. To reduce the maternal morbidity and mortality associated with illegal abortions, the medical termination of pregnancy has been legalized in India when the Government of India passed the Medical Termination of Pregnancy Act in
1971 (MTP). ${ }^{1}$ By definition contraceptives are methods or a system which allows intercourse and yet prevents conception. Unfortunately abortion has become a common method of limiting and spacing birth, but it should on no account to be promoted as a family planning method. $^{2}$

Unfortunately MTP is on its rise as a common method for limiting and spacing births. High rates of induced abortions reflect low prevalence of contraceptive use and their knowledge among the eligible couples. Despite constant efforts by the government, unmet needs still remain. The reasons for these unmet needs have to be analyzed to the core for better understanding of the situation and to help the government in formulation of appropriate policies and modified approaches. 
So this study aimed to know the reasons affecting the outcome of the Family Planning Program in this part of Delhi and to expand our horizon to eliminate the root cause of this problem.

\section{METHODS}

This is a cross sectional study conducted in the department of Obstetrics and Gynaecology, Dr. RML hospital and PGIMER, New Delhi between February 2015 and May 2015. It is a tertiary care hospital and caters the population of central Delhi. Pregnant women coming to the Family Planning OPD for MTP were included in the study. 150 patients were interrogated on a pre-tested pre structured questionnaire. Their knowledge regarding contraception, abortion rules, places, complications, use of contraception, reasons for MTP were asked. The method of termination whether medical or surgical depended upon the POG. For Medical methods WHO 2012 regime was followed which included RU 486, 200mgon day 1 followed by 800 misoprostol on day 3 , completion of abortion was confirmed on day 14 . The surgical method included suction and evacuation which included pre-ripening of the cervix with sublingual $400 \mathrm{mcg}$ misoprost and subsequent evacuation. For second trimester abortion WHO guidelines were followed.

The informed consent and confidentiality of the patients were ensured and the data was analysed by SPSS 15 .

\section{RESULTS}

The socio-demographic characteristics of the group studied are shown in Table 1. Among all the women undergoing MTP, 2\% were in the tender age of 14-19 years, while most of these women were married, $4 \%$ of them were unmarried. Nearly half were either illiterate or studied till primary school $(22 \%, 24.6 \%)$ and only $16.6 \%$ were graduate. The abortion seeking behaviour demonstrated a peak after parity two. MTP was maximum in lower middle class group followed by lower class. Nulliparous women who came for abortions were either unmarried or had marital conflict. Completed family was the leading reason for MTP followed by previous small child (Figure 1). Surprisingly $80 \%$ knew one or the other way of contraception but still $61.3 \%$ were not using any contraception (Table 2). The most common method ever used by the couples was condom (36\%), followed by OCP $(2.6 \%)$. MTP seekers chose temporary method (CuT, 60.6\%) the most than permanent method (36.6\%) (Table 3). $2.6 \%$ did not choose any as they were unmarried but they were counselled for abstinence and risk of unprotected sex was told to them. In addition they were told about the risk of unprotected sex.

Nearly half $(41.3 \%)$ were aware of places where abortions to be conducted but majority (83.3\%) were unaware of abortion complications. Though $80 \%$ felt bad about the abortion but there were still $20 \%$ who were quite ok with it. The important source of knowledge about contraceptive methods was family members, friends and television.

Table 1: Socio-demographic characteristics.

\begin{tabular}{|c|c|c|}
\hline & n & $\%$ \\
\hline \multicolumn{3}{|l|}{ Marital status } \\
\hline Married & 146 & 97.3 \\
\hline Unmarried & 4 & 2.6 \\
\hline \multicolumn{3}{|l|}{ Age group } \\
\hline $15-19$ years & 4 & 2 \\
\hline 20-24 years & 48 & 32 \\
\hline 24-29 years & 37 & 24 \\
\hline 30-34 years & 55 & 36 \\
\hline$\geq 35$ years & 6 & 4 \\
\hline \multicolumn{3}{|l|}{ Parity } \\
\hline p0 & 8 & 5.3 \\
\hline p1 & 33 & 22 \\
\hline p2 & 75 & 50 \\
\hline $\mathrm{p} \geq 3$ & 34 & 22.6 \\
\hline \multicolumn{3}{|l|}{ Education } \\
\hline Illiterate & 33 & 22 \\
\hline Primary school & 37 & 24.6 \\
\hline Secondary school & 55 & 36.6 \\
\hline Graduate & 25 & 16.6 \\
\hline \multicolumn{3}{|c|}{ Socio-economic status } \\
\hline Lower class & 49 & 32.6 \\
\hline Lower middle class & 92 & 61.3 \\
\hline Upper middle class & 9 & 6 \\
\hline \multicolumn{3}{|l|}{ Religion } \\
\hline Hindu & 130 & 86.6 \\
\hline Muslim & 12 & 8 \\
\hline Christian & 3 & 2 \\
\hline Sikh & 5 & 3.3 \\
\hline
\end{tabular}

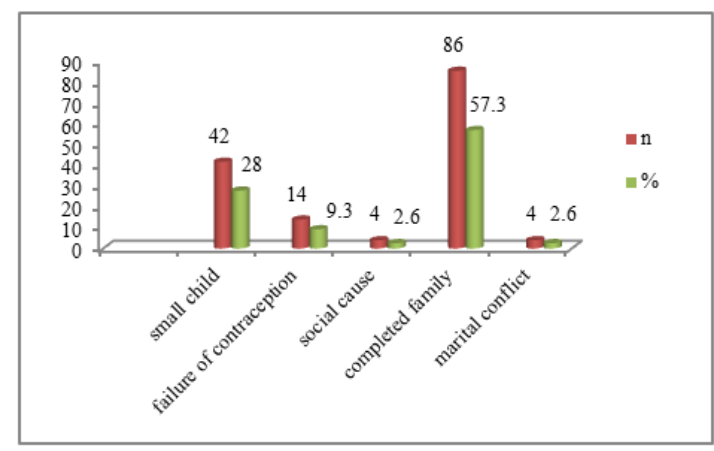

Figure 1: Reasons for MTP.

Table 2: Use of contraception.

\begin{tabular}{|lll|}
\hline Use of contraception & n & $\%$ \\
\hline Nil & 92 & 61.3 \\
\hline Barrier & 54 & 36 \\
\hline OCP's & 4 & 2.6 \\
\hline
\end{tabular}




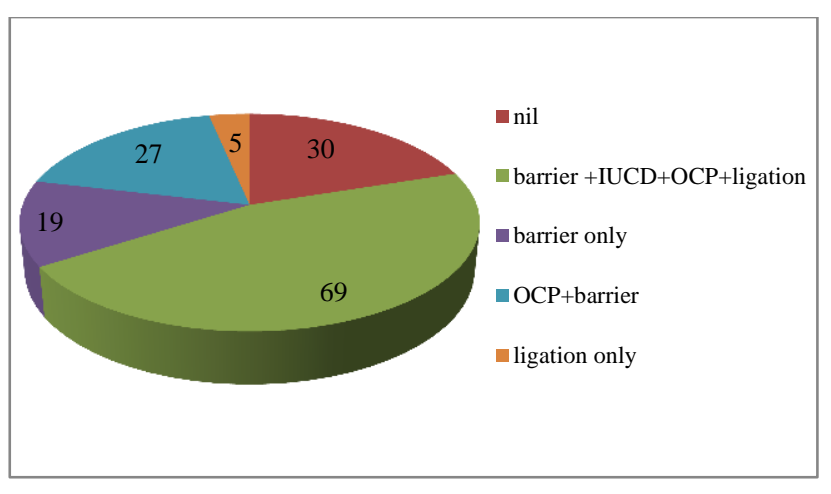

Figure 2: Knowledge of contraception $(n=150)$.

Table 3: Contraception chosen after MTP.

\begin{tabular}{|lll|}
$\begin{array}{l}\text { Contraception } \\
\text { chosen }\end{array}$ & n & $\%$ \\
\hline Cu T & 91 & 60.6 \\
\hline Sterilization & 55 & 36.6 \\
\hline Nil & 4 & 2.6 \\
\hline
\end{tabular}

Table 4: Awareness among women seeking MTP.

\begin{tabular}{|lllll|}
\hline \multirow{2}{*}{ Knowledge } & Yes & \multicolumn{2}{l|}{ No } \\
\hline Abortion complications & n & \% & n & \% \\
\hline Abortion places & 62 & 41.6 & 125 & 83.3 \\
\hline Emergency pill & 38 & 25.3 & 112 & 58.6 \\
\hline
\end{tabular}

\section{DISCUSSION}

Contraception is an important aspect of reproductive health and plays a major role in the prevention of unwanted pregnancy. India was the first country in the world to formulate a national family planning programme in 1952 and due importance to it is given by subsequent five year plannings. ${ }^{3}$ The national population policy 2000 set out a framework for integrated service for the delivery of reproductive health services at various levels within which the demands for contraceptive products and services would be met as fully as possible with due sensitivity to economic realities and in context of different cultures. It is therefore a significant factor in reduction of induced abortion rates and improvement in maternal health care. In spite of the availability of safe and effective contraception, the need for it has not been met mainly due to the ignorance amongst women especially in rural and tribal areas. ${ }^{3}$ The Government of India through the nongovernment organisations and the Federation of Obstetrics and Gynecological Societies of India is trying to meet the remaining need for contraception.

In our study, knowledge of contraception was more but still non-use of a contraceptive at the time of conception was high $(61.3 \%)$ as compared to that in the study by Young et al. (39\%), Aneblom et al. (33\%) and Srivastava Reena et al. (55.2). ${ }^{4-6}$ Majority of women were P2 in our study in comparison to other studies where P3 and P4 were common. ${ }^{4,6}$ which shows the inclination towards small family but may be illiteracy, ignorance, social and religious taboos, and inadequate social welfare services affected their use of contraception. Surprisingly when they were asked about the reason for not using contraception, majority did not give answers and some said the interference of family members. Completed family followed by previous child small were the main indication for MTP, the same were seen by Srivastava et al. $^{6}$ and Parwati et al. ${ }^{7}$

Our study revealed the hard fact that ignorance is not only the problem of rural and tribal areas but the urban area too. Literacy has also not improved the awareness as only $22 \%$ were illiterate in our study and other were literate and $16 \%$ were graduate. Added to our surprise, knowledge of emergency pill was also lacking in $74.6 \%$ of the females. This was also true with other studies. ${ }^{6-8}$

The present study in a New Delhi Hospital suggests a very high prevalence of unwanted pregnancies due to lack of use of regular contraception, lack of knowledge and use of emergency contraception. There is a real need to improve the awareness of women of different methods, regular and emergency contraception to avoid unwanted pregnancies and ill-effects of abortion for unintended pregnancies. The media, the Non-Government Organisations (NGOs) can play a role in popularizing them amongst general population to improve the female healthcare in the larger perspective. The target group should be males in addition to females as women are still fighting for their reproductive rights in our society.

Hence, we recommend sustained efforts to increase awareness and motivation for contraceptive use. This can be brought about by facilitating the access to more information, education and communication with the reproductive age couples, and improved social and welfare services.

\section{CONCLUSION}

Practice of contraception is still a myth. There is a great need to strengthen the awareness among people by various programmes and the target group should be both males and females.

Funding: No funding sources Conflict of interest: None declared

Ethical approval: The study was approved by the institutional ethics committee

\section{REFERENCES}

1. Park K. Medical termination of pregnancy act, 1971. In: Park K, eds. Park's Textbook of Preventive and Social Medicine. 18th ed. Jabalpur: Banarsidas Bhanot; 2005: 371-381. 
2. Henshaw SK, Singh S, Hass T. The incidence of abortion world-wide. Int Fam Plann Perspect. 1999;25(Suppl):530-8.

3. Nanda AR. Understanding the unmet needs for contraception and challenges for meeting the same in India. In: Chatterjee A, Mahapatra PD eds. Obstetrics and Gynecology. Highlights: an Evidence Based Review. 1st ed. Kolkata: Modern Graphica; 2006: 346-354.

4. Young LK, Farguhar CM, McCowan LM, Roberts HE, Taylor J. The contraceptive practice of women seeking termination of pregnancy in an Aukland clinic. NZ Med J. 1994;107:189-92.

5. Aneblom G, Larsson $M$, Odlind $V$, Tydén $T$. Knowledge, use and attitudes towards emergency contraceptive pills among Swedish women presenting for induced abortion. BJOG. 2002;109:155-60.
6. Srivastava R, Srivastava DK, Jina R, Srivastava K, Sharma N, Saha S. Contraceptive knowledge, attitude and practice (KAP) survey. J Obstet Gynaecol India. 2005;55(6):546-50.

7. Parvati V. Bhat, Ashwini Prabhu. Contraceptive knowledge, practice and acceptance. Among women seeking termination of pregnancy at a Secondary level hospital in Southern Karnataka. Health Popul Perspect Issues. 2008;31(3):157-62.

8. Sunita Mittal, Anupama Bahadur, Jai Bhagwan Sharma. Survey of the attitude to, knowledge and practice of contraception and medical abortion in women attending a family planning clinic. J TurkishGerman Gynecol Assoc. 2008;9(1):29-34.

DOI: $10.18203 / 2320-1770 . i j r \operatorname{cog} 20150072$

Cite this article as: Bansiwal $\mathrm{R}$, Singh $\mathrm{P}$, Bajpai S. Practice of contraception in this modern world: still a myth? Int J Reprod Contracept Obstet Gynecol 2015;4:674-7. 